\title{
A Practical Approach for Validation of Aptitude of Sized Carbon Fibers for the In-Mould -Impregnation Process
}

\author{
Andre Ullmer, Tobias Kleffel, Zhanyu Zhai, Tobias Mattner, Dietmar Drummer \\ Institute of Polymer Technology, Friedrich-Alexander-University Erlangen-Nuremberg, Erlangen, Germany \\ Email address: \\ ullmer@lkt.uni-erlangen.de (A. Ullmer) \\ To cite this article: \\ Andre Ullmer, Tobias Kleffel, Zhanyu Zhai, Tobias Mattner, Dietmar Drummer. A Practical Approach for Validation of Aptitude of Sized \\ Carbon Fibers for the In-Mould -Impregnation Process. American Journal of Mechanical and Materials Engineering. \\ Vol. 3, No. 1, 2019, pp. 11-19. doi: 10.11648/j.ajmme.20190301.12
}

Received: January 7, 2019; Accepted: February 19, 2019; Published: March 14, 2019

\begin{abstract}
As a new and innovative processing method for carbon fiber reinforced thermoplastic composites, the In-MouldImpregnation process (IMI) adopts carbon fibers as a heating element by electrical conduction. During heating of the dry carbon fibers in the production process, temperatures up to over $500^{\circ} \mathrm{C}$ can occur. However, the surface properties of carbon fibers and sizing may change under such conditions and thus affect the resulting composite. The present study is a practical approach to validate the suitability of sized carbon fibers for the IMI. The influence of a thermal treatment according to the parameters of the IMI-Process on carbon fiber-thermoplastic matrix interfacial adhesion was investigated by means of micromechanical and optical test methods. The experimental results demonstrate that the thermal treatment of carbon fibers causes a reduction of tensile strength of single fibers. It does not show an influence on the micromechanical breaking behavior in a PA 6 composite but the surface tension of carbon fibers changes. The change in surface tension can affect the wettability of the carbon fiber with a thermoplastic matrix.
\end{abstract}

Keywords: In-Mould-Impregnation, Interfacial Shear Strength, Single Fiber Fragmentation Test, Thermal Treatment, Fiber-Matrix Adhesion

\section{Introduction}

Polyamides (PA) are used in a wide range of applications in different areas such as the automotive sector, aviation, sport textiles and sport utility industries [1-4]. Especially if a thermoplastic polymer (like PA 6) is combined with a fiber, outstanding performance can be achieved in terms of weight specific strength and rigidity [4]. Nevertheless the economic production of thermoplastic continuous fiber reinforced composite parts is still challenging due to the requirement and production costs of semi-finished products (like organo sheets). One new and innovative way to omit the production of semi-finished parts and to produce thermoplastic continuous fiber reinforced composites in a one-step process is the IMI [5]. In this process a non-crimp carbon fabric is impregnated with the thermoplastic matrix within the injection mold. For this purpose, the non-crimp carbon fabric is heated up in the injection mold by current power, using the electric resistance of the carbon. To process a PA 6 composite in IMI, a temperature of $280^{\circ} \mathrm{C}$ for the carbon fibers is needed. Preliminary investigations showed that within a dry roving, varying temperatures up to over $500^{\circ} \mathrm{C}$ can occur depending on whether a fiber has contact to the tool or faces the air side during the preheating period of IMI, Figure 1. To improve the fiber wetting ability and fiber-matrix interfacial adhesion, chemical and physical treatments are usually applied to fibers during the manufacturing procedure (also called sizing). However, the sizing of carbon fibers may change through the expose to elevated temperatures over $500^{\circ} \mathrm{C}$ and thus affect the properties of the resulting composites. 
a)
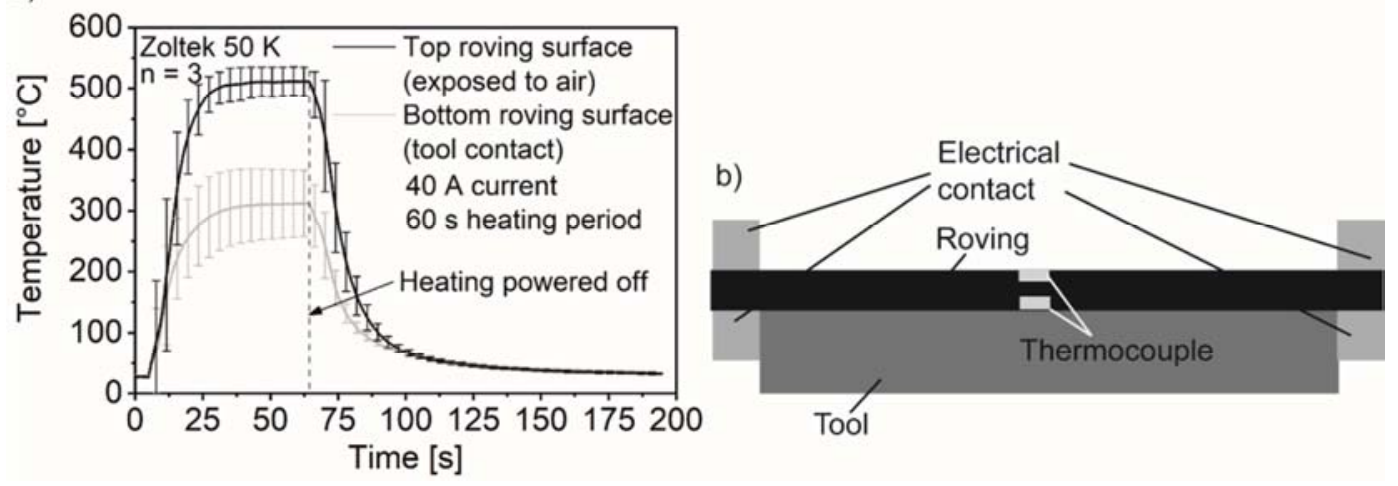

Figure 1. a) Temperature development on top and at the bottom of a dry carbon fiber roving (Zoltek $50 \mathrm{~K}$ ) at the heating period according to the IMI. Minimum target temperature $280^{\circ} \mathrm{C}$ for example for PA 6. b) Setup for measurement of temperatures during preheating period for the IMI.

In numerous reports [6-10], different surface treatments for carbon fibers to improve the bonding to epoxy resins (thermosets) are well analyzed. However, investigations of surface treatments for carbon fibers for the bonding with thermoplastic polymers are scarce, even though a wide range of carbon rovings with numerous sizings designed for thermoplastic polymers are already available on the market. The sizings consist of different elements and reactive groups depending on their application case. Most sizings are organobased materials. Due to their structural resemblance to the polymer matrix, different adhesion mechanisms appear like van der Waals interaction. Examples for sizings are emulsions of silane oil for combinations of glass fibers with epoxy resin matrix [11] or emulsions based on polyetherimide for combinations of carbon fibers with thermoplastic matrix [12].

In the present paper, a practical approach to validate the aptitude of sized carbon fibers for IMI is investigated. Firstly, the thermal limit of the different carbon fiber sizing types was investigated by thermogravimetric analysis. Afterwards, the interfacial shear strength (ISS) of carbon-PA 6 composites with thermally untreated and treated carbon fibers was quantified with single filament tension (SFTT) and single fiber fragmentation tests (SFFT). The SFFT is an established method to assess the interfacial adhesion between polymers and fibers [13]. In addition, changes of the surface tension and thus changes of the wettability were investigated using the capillary method.

\section{Experimental}

\subsection{Used Materials}

In this investigation, a thermoplastic polymer and two different types of carbon fibers were used. A PA 6 type Durethan B30S from Lanxess AG (Cologne, Germany) was used as thermoplastic matrix material. The investigated single carbon fibers were taken out of carbon rovings of the type PXTW 35 from Zoltek Corporation (Bridgeton, USA) with a single fiber diameter of $7.2 \mu \mathrm{m}$ and type HTS $4512 \mathrm{~K}$ from Toho Tenax Cp., Ltd. (Chiyoda, Japan) with a single fiber diameter of $7.0 \mu \mathrm{m}$. The sizing of both carbon roving types are compatible with thermoplastic matrices like PA 6, PA 6.6, PEI or PEEK according to the manufacturer.

\subsection{Samples Preparation}

\subsubsection{Samples for Measuring of the Surface Tension}

For the preparation of the samples for the measurement of the surface tension, pieces of $60 \mathrm{~mm}$ length are cut out from each roving type. Afterwards, the single fibers of each roving piece are geometrically fixed at the ends using a glue of the type Pattex Kraftkleber classic (Henkel AG \& Co. KGaA, Dusseldorf, Germany), Figure 2. The used glue features a relatively high viscosity compared to other glues tried in this investigation, which is needed to avoid an influence on the surface tension measurements due to capillary effects.

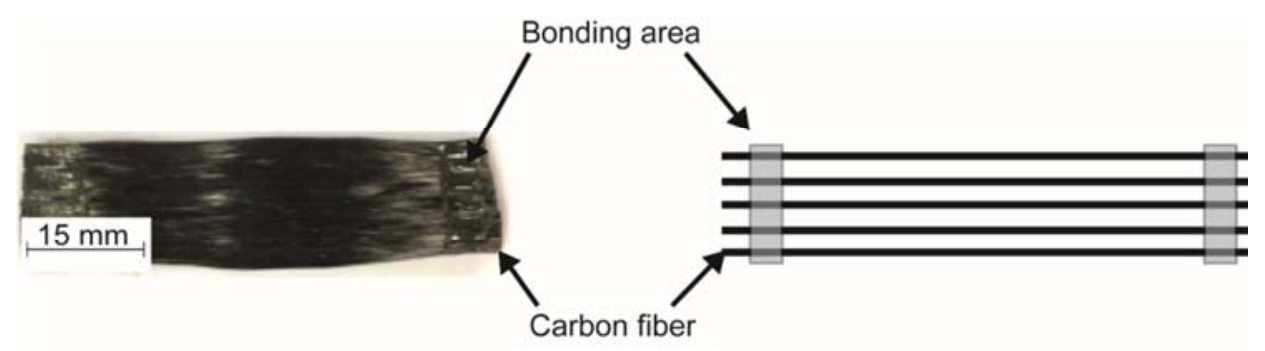

Figure 2. Schematic illustration (right) and example (left) of a sample for measuring of the surface tension (right).

\subsubsection{Samples for Single Fiber Tension Tension Tests and Single Fiber Fragmentation Tests}

To produce the thermally treated carbon fibers for the
SFTT and SFFT, carbon fiber rovings of both types (PXTW $3550 \mathrm{~K}$, HTS $4512 \mathrm{~K}$ ) were heated by connecting the ends of each roving to a current power supply of the type 
C10kW/20-500 from Power Control Electronic GmbH \& Co. KG (Reutlingen, Germany) for $60 \mathrm{~s}$, Figure 1. In order to guarantee that each carbon fiber reached a minimum of $500^{\circ} \mathrm{C}$, a current of $40 \mathrm{~A}$ was used for the type PXTW 35 and a current of $11 \mathrm{~A}$ was used for the type HTS 45 (the required currents have been identified in pre-trials using temperature surveillance with thermocouples and a thermographic camera).

For the manufacturing of SFFT-samples, groups of single fibers were taken out of thermally untreated and treated rovings and placed between two PA 6 films, two polytetrafluoroethylene (PTFE)-films and two metal sheets as shown in Figure 3 a. The PA 6 films were conditioned for 48 $\mathrm{h}$ at $80^{\circ} \mathrm{C}$ to ensure a dry sample condition for manufacturing. Afterwards, the described packages were manufactured to carbon fiber-PA 6 composites using a hot press of the type APU 100x HPV from Blue Tiger System GmbH (Bremen, Germany). The process parameters are given in Table 1.

Table 1. Process parameters for the manufacturing of the micro carbon fiber-PA 6 composites.

\begin{tabular}{lll}
\hline Parameter & Heating period & Cooling period \\
\hline Temperature $\left[{ }^{\circ} \mathrm{C}\right]$ & 260 & 80 \\
Pressure $\left[\mathrm{N} / \mathrm{mm}^{2}\right]$ & 0.2 & 0.2 \\
Holding time $[\mathrm{s}]$ & 600 & 180 \\
\hline
\end{tabular}

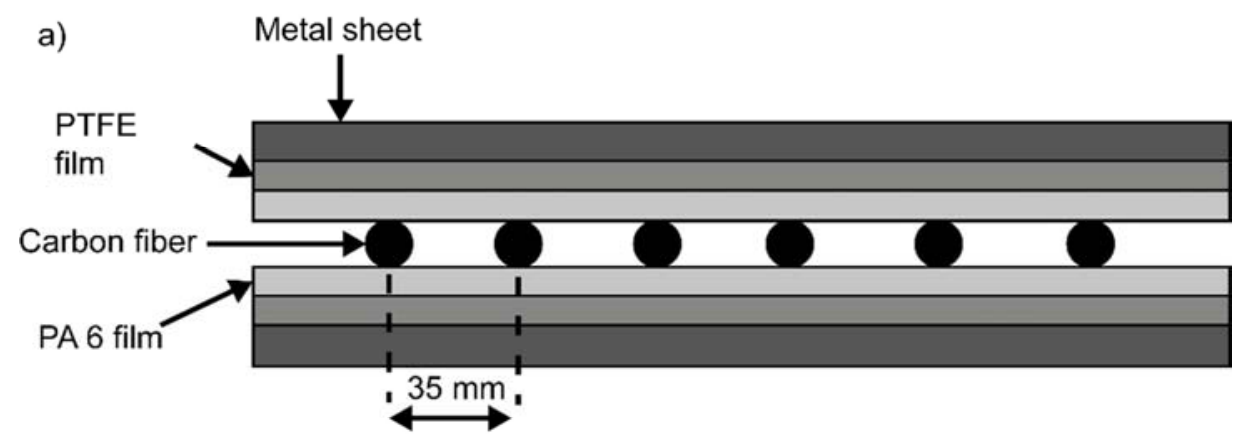

b)

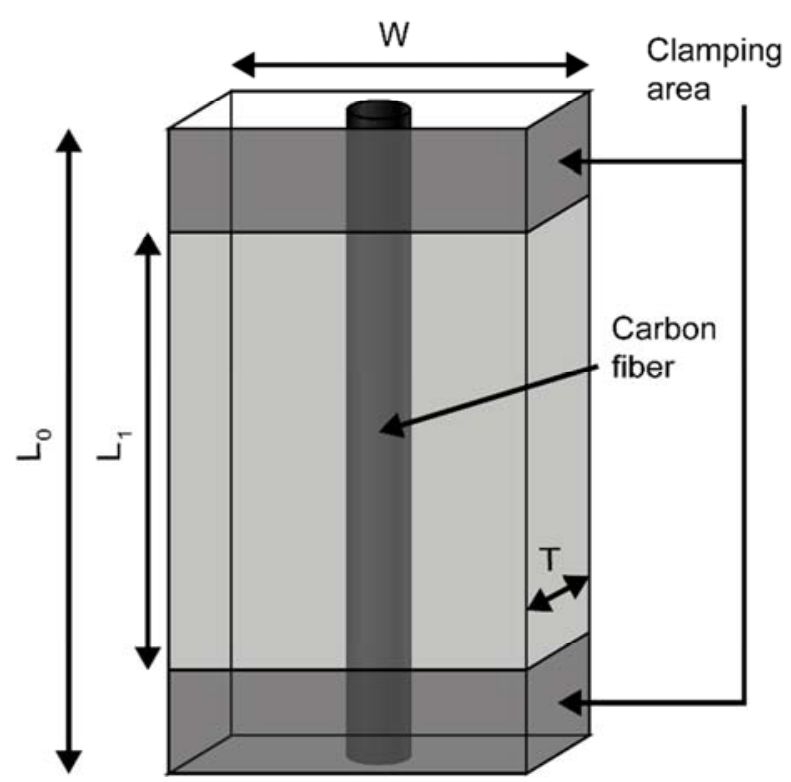

Figure 3. Schematic illustration of a) a material package for the manufacturing of the micro carbon fiber-PA 6 composite, b) architecture and dimensions of a SFFT sample.

Finally, the single SFFT samples with the total length $\mathrm{L}_{0}=$ $60 \mathrm{~mm}$, gauge length $\mathrm{L}_{1}=30 \mathrm{~mm}$, width $\mathrm{W}=15 \mathrm{~mm}$ and depth $\mathrm{T}=0.4 \mathrm{~mm}$ were cut out of the micro CF-PA 6 composite sheets, Figure 3 b.

For the tensile tests, all SFFT-samples were conditioned to equilibrium moisture content according to DIN EN ISO 1110 .

\subsection{Test Methods}

\subsubsection{Thermo-Gravimetric Analysis}

For the thermal behavior of the sizing until $500^{\circ} \mathrm{C}$ according to the maximal temperature during IMI, a thermogravimetric analysis (TGA) according to DIN EN ISO 11358-1 was used. The investigations were conducted with a test instrument of the type TGA Q 5000 from TA Instruments 
Inc. (New Castle, USA) with air environment and a heating rate of $0.33 \mathrm{~K} / \mathrm{s}$. The heating range was $23^{\circ} \mathrm{C}$ to $600^{\circ} \mathrm{C}$. From each roving type, a $60 \mathrm{~mm}$ long unheated sample was investigated.

\subsubsection{Determination of the Surface Tension}

The capillary method was used to detect the potential influence of the thermal degradation of the fiber sizing on the surface tension. With this method, the contact angle can be calculated based on the meniscus of a testing fluid on the sample. The basic requirement for the formation of the meniscus is that the surface tension of the testing fluid is higher compared to the surface tension of the investigated sample. Due to its higher surface tension and incapability to solve carbon fibers, distilled water was used as the testing fluid.

For the measurement of the surface tension, the sample is immersed into the testing fluid, followed by a short pull out, which leads to the formation of the so-called retracting angle [13]. In order to avoid a capillary effect between the single fibers of the sample, a setting time takes place between the immersion and the short pull out until the capillary effect is static. The height of the meniscus of the testing fluid on the sample is optically determined and the contact angle can be calculated with the following formula $[14,15]$ :

$$
\theta=\arcsin \left(1-\frac{\rho * \mathrm{~g} * \mathrm{~h}^{2}}{2 * \sigma_{1}}\right)
$$

where

$\theta$ - Contact angle $\left[^{\circ}\right]$

$\rho$ - Density of the testing fluid $\left[\mathrm{g} / \mathrm{cm}^{3}\right]\left(\rho=0.9882\right.$ at $20^{\circ} \mathrm{C}$ according to [16])

g - Gravitational constant $\left[\mathrm{m} / \mathrm{s}^{2}\right]$

$\mathrm{h}$ - Height of the meniscus [mm]

$\sigma_{1}$ - Surface tension of the testing fluid $[\mathrm{mN} / \mathrm{m}]\left(\sigma_{1}=72.10\right.$ $\mathrm{mN} / \mathrm{m}$ at $20^{\circ} \mathrm{C}$ according to [16])

Afterwards, the contact angle can be used to calculate the surface tension of the sample according to the Neumann Formula [15]:

$$
\cos \theta=-1+2 \sqrt{\frac{\sigma_{s}}{\sigma_{l}}} * \mathrm{e}^{-\beta\left(\sigma_{1}-\sigma_{\mathrm{s}}\right)^{2}}
$$

where

$$
\begin{aligned}
& \sigma_{\mathrm{s}} \text { - Surface tension of the sample }[\mathrm{mN} / \mathrm{m}] \\
& \beta \text { - Constant: } 0.0001247(\mathrm{~m} / \mathrm{mN})^{2} \text { (empirically determined) }
\end{aligned}
$$

\subsubsection{Microscopic Analysis}

For the microscopic analysis, a scanning electron microscopy (SEM) of the type Ultra plus from Carl Zeiss NTS GmbH (Oberkochen, Germany) with energy dispersive $\mathrm{X}$-ray analysis (EDX) was used to detect changes of the sizing on the thermally untreated and treated carbon fibers. As mentioned in chapter 1 , sizings contain the element oxygen $(\mathrm{O})$ especially in $(-\mathrm{OH})$ groups for the chemical and physical adhesion. Hence, the presence of oxygen is evaluated with an EDX-analysis.

\subsubsection{Single Fiber Tension Test}

The SFTT was conducted on a universal testing machine of the type Instron 5948 from Instron $\mathrm{GmbH}$ (Darmstadt, Germany) with standard atmosphere $\left(23^{\circ} \mathrm{C}\right.$ and $50 \%$ humidity) according to ASTM D3379-75 and a gauge length of $30 \mathrm{~mm}$. Each single fiber was selected randomly from the roving and glued vertically centered and straightened to a slotted card. These slotted cards were mounted in the clamping of the testing machine in such way that the single fiber was aligned axially to the tension direction. A total of 100 samples each of thermally untreated and treated fibers of both fiber types were tested. The failure probability of the fibers at the gauge length under an applied stress smaller or equal to the tensile strength of the fiber was statistically analyzed using a two parameter Weibull distribution [17] according to $[18,19]$ :

$$
\mathrm{F}(\sigma)=1-\exp \left[\left(-\mathrm{L}_{0}\right)\left(\frac{\sigma}{\sigma_{0}}\right)^{\mathrm{m}}\right]
$$

where

F - Failure probability of the fibers at the gauge length

$\mathrm{L}_{0}$ - Gauge length [mm]

$\sigma$ - Tensile strength of the fiber $\left[\mathrm{N} / \mathrm{mm}^{2}\right]$

$\sigma_{0}$ - Scale parameter of the Weibull distribution

$\mathrm{m}$ - Shape parameter of the Weibull distribution

Besides the failure probability of the fibers at the gauge length, the average tensile strength of the fibers was analyzed, which can be calculated with the following formula:

$$
\sigma_{\mathrm{f}}(\mathrm{L})=\sigma_{0}\left(\frac{\mathrm{L}_{0}}{\mathrm{~L}}\right)^{\frac{1}{\mathrm{~m}}} \Gamma\left(1+\frac{1}{\mathrm{~m}}\right)
$$

where

$$
\begin{aligned}
& \sigma_{\mathrm{f}} \text { - Average tensile strength }\left[\mathrm{N} / \mathrm{mm}^{2}\right] \\
& \mathrm{L} \text { - Length of the fiber }[\mathrm{mm}] \\
& \Gamma \text { - Gamma function }
\end{aligned}
$$

\subsubsection{Single Fiber Fragmentation Tests}

The SFFTs were conducted on the same universal testing machine as the previously stated ones with standard atmosphere $\left(23^{\circ} \mathrm{C}\right.$ and $50 \%$ humidity) according to ASTM D3379-75. In total, a number of 9 samples were tested up to a tensile strain of $25 \%$, which is far higher than the ultimate tensile strain of the carbon fiber. The critical fiber length was detected by transmitted light microscopy using a microscope of the type AxioImagerM2 from Carl Zeiss Microscopy GmbH (Jena, Germany). Furthermore, the ISS of the fibermatrix interface can be estimated from the Kelly and Tyson equation [20]:

$$
\tau=\frac{\sigma_{\mathrm{f}}\left(\mathrm{L}_{\mathrm{c}}\right) \mathrm{d}}{2 \mathrm{~L}_{\mathrm{c}}}
$$

where

$\tau$ - Interfacial shear strength $\left[\mathrm{N} / \mathrm{mm}^{2}\right]$

$\mathrm{L}_{\mathrm{c}}$ - Critical length of the fiber $[\mathrm{mm}]$

$\mathrm{d}$ - Fiber diameter [mm]

The critical length $L_{c}$ was determined by the following 
equation:

$$
\mathrm{L}_{\mathrm{c}}=\frac{4 \mathrm{~L}^{\prime}}{3}
$$

where

$\mathrm{L}^{\prime}$ - Median length of the fiber fragments in a SFFT sample [mm]

The choice of the median instead of the arithmetic average of the measured fiber length is constituted in the robustness of the median against outliers in the measurement.

\section{Results and Discussion}

\subsection{Thermal Stability of the Carbon Fiber Sizing}

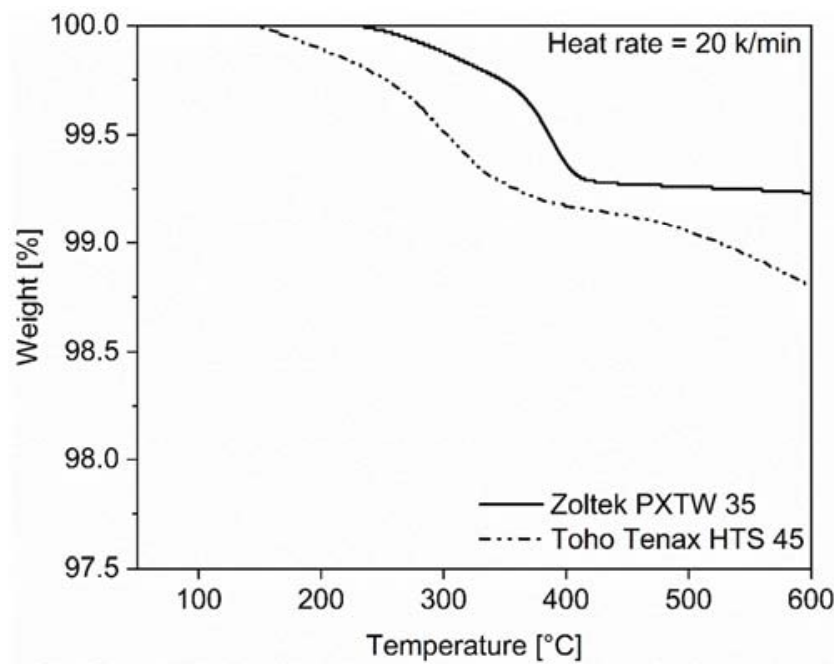

Figure 4. Weight temperature curves of the carbon fiber types Zoltek PXTW 35 and Toho Tenax HTS 45.

The results of the TGA of both carbon fiber types, Figure 4 , show a weight reduction with a rising temperature until $600^{\circ} \mathrm{C}$. The starting point of the weight reduction, which is most likely caused by a thermal degradation of the sizing, is located at approximately $250^{\circ} \mathrm{C}$ for the fiber type Zoltek PXTW 35 and approximately $150^{\circ} \mathrm{C}$ for the fiber type Toho Tenax HTS 45 . At $400^{\circ} \mathrm{C}$, the weight reduction of the fiber type Zoltek PXTW 35 stops and the relative weight remains roughly at the same level until $600^{\circ} \mathrm{C}$, which is a clue that the sizing is completely thermally degraded. In contrast, the weight reduction of the fiber type Toho Tenax HTS 45 shows an ongoing decrease of the weight until the end of the measurement at $600^{\circ} \mathrm{C}$, which is a clue that different thermochemical processes take place, which are not completed when the final temperature of $600^{\circ} \mathrm{C}$ is reached. Furthermore, the fibers of type Toho Tenax HTS 45 experience a bigger weight reduction than the fibers of type Zoltek PXTW 35 at $600^{\circ} \mathrm{C}$, which could indicate that the fiber type Toho Tenax HTS 45 has a higher relative sizing content than the fiber type Zoltek PXTW 35 at the initial state, assuming the sizing is incinerated. The aim of this investigation is not to detect how the fiber and its sizing is changing chemically. It just indicates that there is a change to the initial fiber state due to the thermal treatment. This change is assumed to originate in the thermal degradation of the fiber sizing, which can lead to a change in fiber matrix adhesion.

\subsection{Optical Analyses}

Figure 5 shows a characteristic SEM image of untreated fibers of the fiber type Zoltek PXTW 35 and the areas for the EDX-analyses. The surface of the untreated fiber, Figure 5, appears more rugged than the surface of the thermally treated fiber, which in comparison shows a smoother surface morphology, Figure 6 The EDX-analyses of the untreated fibers, Figure 5 right, show that the fiber surface is characterized by carbon (C) and oxygen contents. The platinum $(\mathrm{Pt})$ and palladium $(\mathrm{Pd})$ content occur as a result of the sample preparation for SEM. According to [10], carbon and oxygen are common components of fiber sizings. In contrast, the EDX-analysis of the thermally treated carbon fibers shows no oxygen content, which is, besides the results of the TGA analyses, a second indicator that the sizing is incinerated and there is no sizing left on the fibers after the thermal treatment.
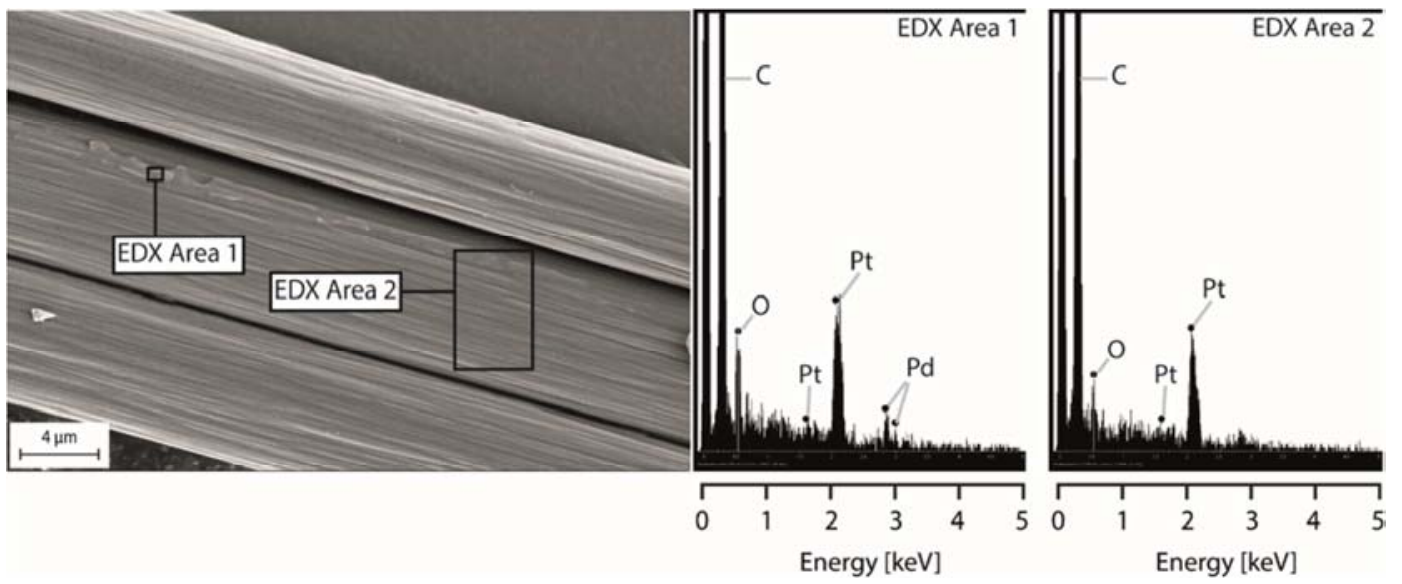

Figure 5. Characteristic SEM image with indication of the areas for the EDX analyses of untreated fibers of the fiber type Zoltek PXTW 35 with respective EDX-analyses results. 


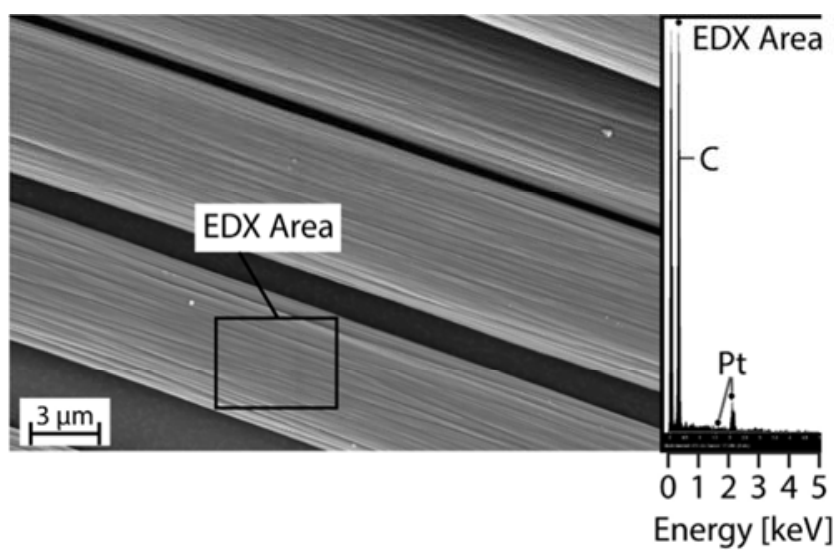

Figure 6. Characteristic SEM image with indication of the area for the EDX analyses of treated fibers of the fiber type Zoltek PXTW 35 with respective EDXanalysis result.

The SEM image of the untreated fiber type Toho Tenax HTS 45, Figure 7, shows similar results of the surface morphology like the Zoltek PXTW 35. In comparison to the surface morphology of the untreated fibers, the surface of the thermally treated fiber appears to be smoother, Figure 8.

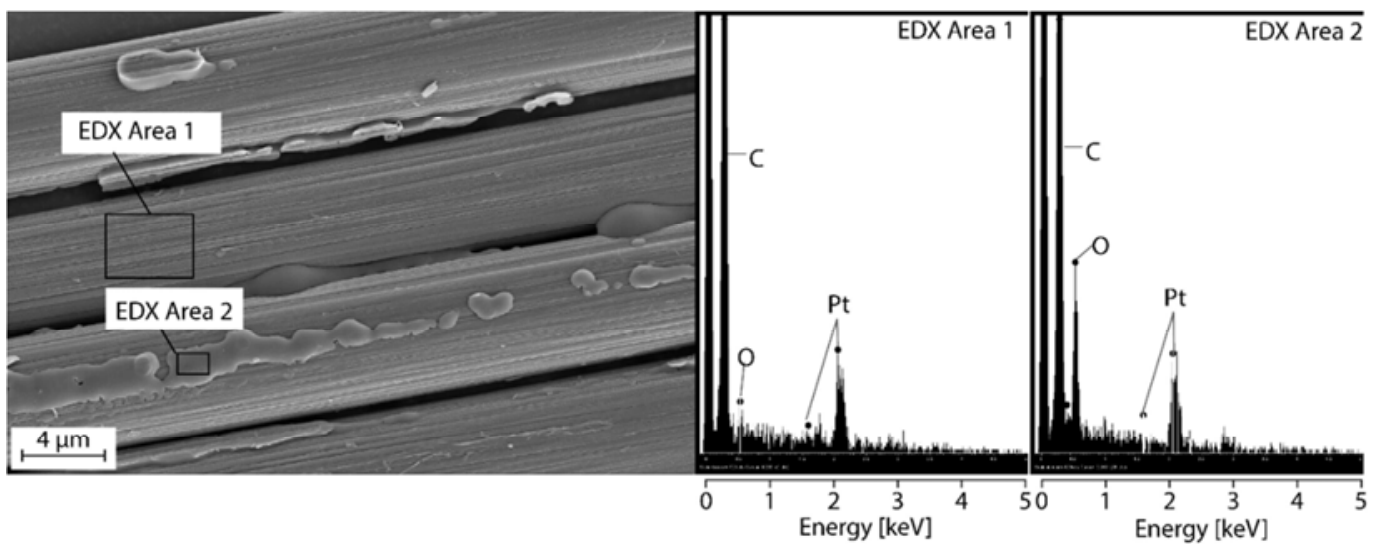

Figure 7. Characteristic SEM image with indication of the areas for the EDX analyses of untreated fiber type Toho Tenax HTS 45 with respective EDXanalyses results.

However, the thermally treated fiber still shows parts of fiber sizing appearing in a droplet-shape. As seen in Figure 4 the percentage weight of the Toho Tenax HTS 45 does not end in a plateau at the end of the respective measurement. This means that there are parts of the sizing which can endure high temperatures, as seen in Figure 8 left. The EDX-analyses show carbon and oxygen contents for both fiber constitutions in the respectively marked areas, which means that there is still sizing left on the thermally treated Toho Tenax HTS 45, albeit possibly in a thermally degraded state.

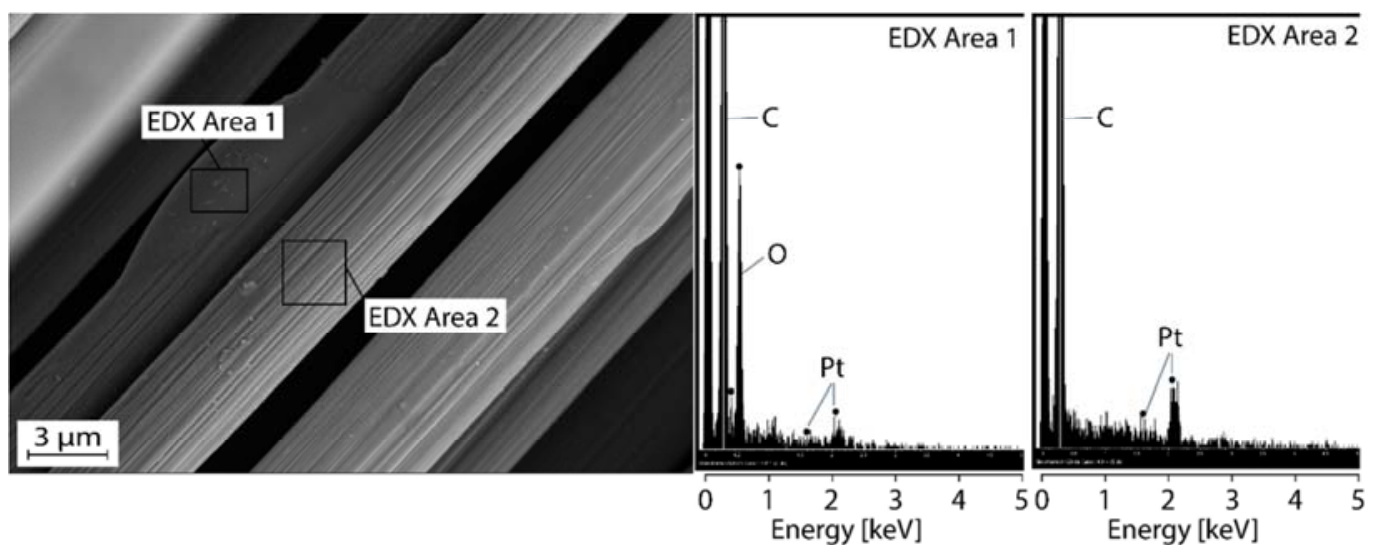

Figure 8. Characteristic SEM image with indication of the areas for the EDX analyses of treated fiber type Toho Tenax HTS 45 with respective EDX-analyses results. 


\subsection{Surface Tension}

The results of the measurement of the surface tension of both fiber types with untreated and thermally treated fibers are shown in Figure 9 It can be seen that the thermally treated fibers tend to have a higher surface tension compared to the respectively untreated fibers which can lead to a worse wettability. In [21] it is investigated that a higher surface tension can be explained by the change of surface morphology. Due to the thermal treatment, the surface morphology gets smoother at both fiber types which leads to a higher surface tension and worse wettability, Figure 6 and Figure 8 .

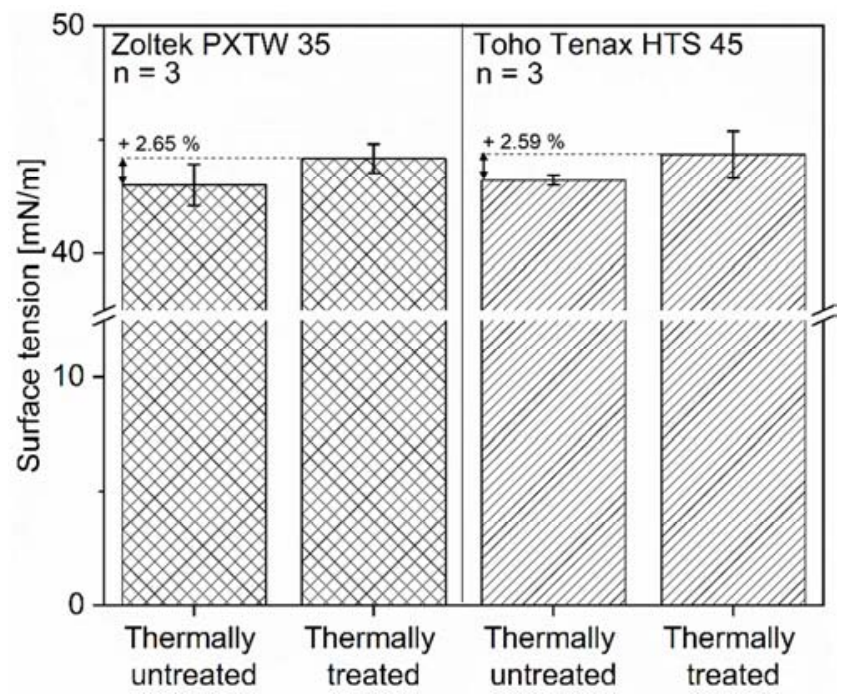

Figure 9. Surface tension of untreated and thermally treated rovings of the fiber type Zoltek PX 35 (left) and Toho Tenax HTS 45.

\subsection{ISS of Carbon Fiber-PA 6 Interfaces with Different Thermal Treatment of the Carbon Fibers}

\subsubsection{Failure Probability of the Carbon Fibers}

The tensile strength distributions of single carbon fibers of the fiber type Zoltek PXTW 35 and Toho Tenax HTS 45 are shown in Figure 10. In both cases, the tensile strength of single fibers follows a Weibull distribution. For the fiber type Zoltek PXTW 35, Figure 10 left, the scale parameter $\sigma_{0}$ is determined to $4318 \mathrm{MPa}$ (thermally untreated) and $4142 \mathrm{MPa}$ (thermally treated) and for the fiber type Toho Tenax HTS 45 to $3880 \mathrm{MPa}$ (thermally untreated) and $3489 \mathrm{MPa}$ (thermally treated) respectively. The shape parameter $\mathrm{m}$ is 5.16 (thermally untreated) and 5.93 (thermally treated) for the fiber type Zoltek PXTW 35 and 6 (thermally untreated) and 5.6 (thermally treated) for the fiber type Toho Tenax HTS 45, which were obtained via least squares regression analysis. Most single fibers of the fiber type Zoltek PXTW 35 (thermally untreated and thermally treated) failed below 5500 $\mathrm{MPa}$. The inclination of failure probability versus the applied stress in the area from $3500 \mathrm{MPa}$ to $5000 \mathrm{MPa}$ is elevated compared to single fibers which failed at lower or higher stress. The same behavior can be seen for the Toho Tenax HTS 45. Here, most fibers (thermally untreated and thermally treated) failed below $4500 \mathrm{MPa}$ and the inclination of failure probability is higher in the range of $3000 \mathrm{MPa}$ to $4250 \mathrm{MPa}$. The resulting $\sigma_{0}$ of each fiber type (thermally untreated and thermally treated) is used in equation (4) to determine average tensile strength of each fiber to calculate the ISS (equation (5)). For both fiber types, the influence of the sizing on the tensile strength is negligible because the sizings do not fully coat the fibers and only occur locally on the fibers as it can be seen in Figure 5 to Figure 8.

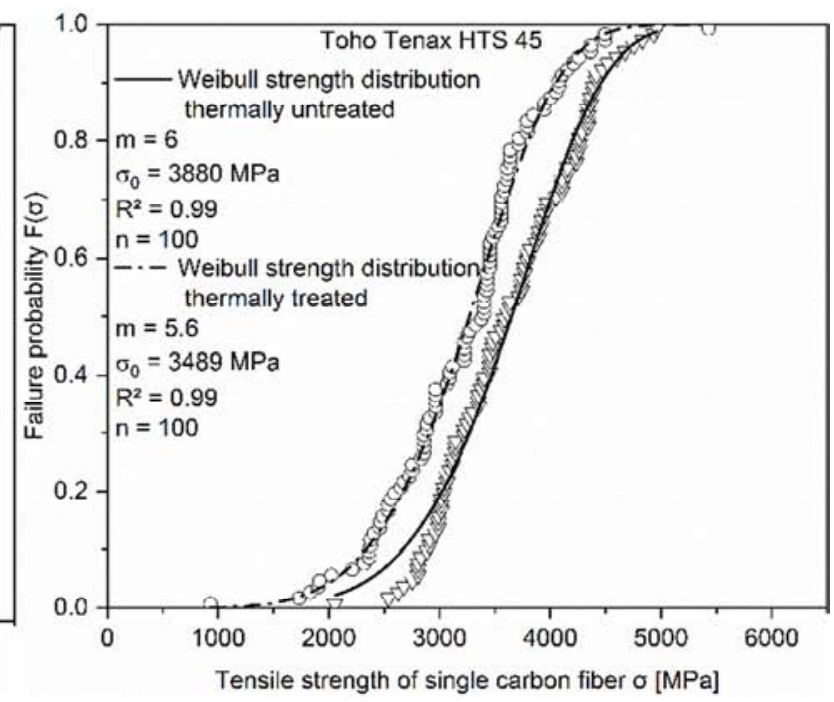

Figure 10. Failure probabilities of thermally treated and untreated carbon fiber Zoltek PXTW 35 (left) and Toho Tenax HTS 45 (right).

\subsubsection{Critical Length of the Carbon Fibers}

The fiber breakage cannot be detected by (polarized) optical stereo-microscopy at the samples in the state present directly after the tension tests have been conducted, because the gap between the carbon breakage filaments is too narrow. Thus, the samples were melted up again between two object slides, pushed gently together and cooled down afterwards. This procedure ensures that the spacing between broken filament segments increases alongside the induced polymeric 
flow, leading to randomly oriented fiber segments, which can be measured with an optical stereo microscope. Due to the manual operation involving only minimal forces and shear rates, additional fiber breakage in this additional preparation step can be excluded. The critical fiber length and the resulting ISS of the untreated and thermally treated carbon fibers in combination with the used PA 6 are summarized in Table 2. The ISS is calculated with the equations (3) to (6). It can be seen that there is no significant difference in ISS between the untreated and thermally treated fibers in combination with PA 6.

Table 2. Mean Median of the critical fiber length of untreated and thermally treated fibers of the fiber types Zoltek PXTW 35 and Toho Tenax HTS 45 and mean ISS of these fiber types with PA 6.

\begin{tabular}{llll}
\hline Type & Thermal treatment & Median of the critical fiber length $\boldsymbol{L}_{\boldsymbol{c}}[\boldsymbol{\mu} \mathbf{m}](\mathbf{n}=\mathbf{9})$ & ISS $\boldsymbol{\tau}[\mathbf{M P a}](\mathbf{n}=\mathbf{9})$ \\
\hline \multirow{2}{*}{ Zoltek PXTW 35 } & no & $648 \pm 68$ & $50.5 \pm 5.3$ \\
& yes & $677 \pm 80$ & $41.8 \pm 5.0$ \\
\multirow{2}{*}{ Toho Tenax HTS 45 } & no & $649 \pm 61$ & $39.6 \pm 3.7$ \\
& yes & $642 \pm 46$ & $37.8 \pm 2.2$ \\
\hline
\end{tabular}

The values of the ISS for thermally untreated und thermally treated carbon fibers in combination with PA 6, shown in Table 2, are comparable to the findings $\left(\mathrm{ISS}_{\text {untreated }}\right.$ $=35-40 \mathrm{MPa}, \mathrm{ISS}_{\text {treated }}=45 \mathrm{MPa}$, measured with single fiber pull-out test) of [22] and [23] respectively.

\section{Conclusion}

In this investigation, the suitability of sized carbon fibers for the In-Mould-Impregnation Process was investigated by means of micro-mechanical and analytical methods, like SFTT to determine the failure probability, SFFT to determine critical fiber length and thus the ISS, thermogravimetric analyses to determine the thermal degradation of the fiber sizing and capillary tests to determine the surface tension of the respective carbon fibers. The main conclusions are as follows.

First, the thermal degradation of the fiber sizing of the investigated carbon fiber types Zoltek PXTW 35 and Toho Tenax HTS 45 starts before reaching the processing temperature of the used PA $6\left(280^{\circ} \mathrm{C}\right.$ according to the IMI).

Second, pre-heating to temperatures of $500^{\circ} \mathrm{C}$ causes the surface of the carbon fibers of both fiber types to change only barely, resulting in a partially smoother surface.

Third, the surface tension of both fiber types is increased after the thermal treatment, which can lead to a worse wettability.

Fourth, the tensile strength of both single carbon fiber types is reduced by thermal treatment. This effect is only minor, though, and can be expected to show major variation depending on the chemical composition of the sizing, the reached temperature levels and the duration of exposition to these elevated temperatures.

Finally, no significant changes of the ISS can be detected for thermally treated fibers of both fiber types using the SFFT. Hence, the specific temperature range of the investigated carbon fibers for the IMI-process $\left(\mathrm{T}_{\text {carbonfibermax }}=\right.$ $500^{\circ} \mathrm{C}$ ) does not influence the ISS in these specific carbon fiber-PA 6-composites for the investigated quasi-static loads.

While most effects reported in this study are minor, the presented methods are found feasible for a process related quantification of the impact of elevated temperatures on the fiber and fiber-matrix-interface properties. Most sizings can be expected to experience major degradation during the process. While the change in mechanical properties due to this is minor for the given case, other sizings as the ones used in the evaluated commercial fiber systems may show higher benefits to the total mechanical properties of the composite. In these cases, the presented methodology is found to be suitable to detect changes in the mechanical properties due to processing, so that parts can be designed accordingly.

\section{Acknowledgements}

This work has been funded by the program "Energie" hosted by Bundesministerium für Wirtschaft und Energie in the project TC-Fast (funding indicator: 03ET1404A-I) and supervised by Projekträger Jülich. We want to thank Audi AG, Christian Karl Siebenwurst GmbH \& Co. KG, Gubesch Thermoforming $\mathrm{GmbH}$, Neue Materialien Fürth GmbH, Plastic Omnium Auto Components GmbH, Saertex GmbH \& und Co. KG, Simpatec Simulation \& Technology Consulting $\mathrm{GmbH}$ and Weilburger Coatings $\mathrm{GmbH}$ for constant collaboration in the project TCFast, which has led to this study.

\section{References}

[1] “Anjamid PA 6 for automotive applications," Plastics, Additives and Compounding, vol. 9, no. 3, p. 21, 2007.

[2] R. Boyer, "Aircraft Materials," in Encyclopedia of Materials: Science and Technology: Elsevier, 2001, pp. 66-73.

[3] E. Matoso and S. Cadore, "Determination of inorganic contaminants in polyamide textiles used for manufacturing sport T-shirts," (eng), Talanta, vol. 88, pp. 496-501, 2012.

[4] S. Yu, W. M. Yek, S. Y. Ho, S. A. D. Rannou, and S. H. Lim, "Microstructure and impact strength of polyamide 6 composites," Materials Today Communications, vol. 4, pp. 199-203, 2015.

[5] J. Reddemann, Beitrag zum energieeffizienten Einsatz von Thermoplast-CFK im Automobilbau, 1st ed. Göttingen: Cuvillier Verlag, 2016.

[6] Y. Gu, H. Liu, M. Li, Y. Li, and Z. Zhang, "Macro- and microinterfacial properties of carbon fiber reinforced epoxy resin composite under hygrothermal treatments," Journal of Reinforced Plastics and Composites, vol. 33, no. 4, pp. 369379, 2013. 
[7] Z. Dai et al., "Effect of heat treatment on carbon fiber surface properties and fibers/epoxy interfacial adhesion," Applied Surface Science, vol. 257, no. 20, pp. 8457-8461, 2011.

[8] V. Rao and L. T. Drzal, "The Temperature Dependence of Interfacial Shear Strength for Various Polymeric Matrices Reinforced with Carbon Fibers," The Journal of Adhesion, vol. 37, no. 1-3, pp. 83-95, 1992.

[9] H. J. Fu, Y. D. Huang, and L. Liu, "Influence of fibre surface oxidation treatment on mechanical interfacial properties of carbon fibre/ polyarylacetylene composites," Materials Science and Technology, vol. 20, no. 12, pp. 1655-1660, 2013.

[10] J. Moosburger-Will et al., "Interaction between carbon fibers and polymer sizing: Influence of fiber surface chemistry and sizing reactivity," Applied Surface Science, vol. 439, pp. 305312, 2018.

[11] G. W. Ehrenstein, Faserverbund-Kunststoffe: Werkstoffe, Verarbeitung, Eigenschaften, 2nd ed. München, Wien: Hanser, 2006.

[12] I. Giraud, S. Franceschi-Messant, E. Perez, C. Lacabanne, and E. Dantras, "Preparation of aqueous dispersion of thermoplastic sizing agent for carbon fiber by emulsion/solvent evaporation," Applied Surface Science, vol. 266, pp. 94-99, 2013.

[13] D. TRIPATHI and F. R. JONES, "Single fibre fragmentation test for assessing adhesion in fibre reinforced composites," Journal of Materials Science, vol. 33, no. 1, pp. 1-16, 1998.

[14] D. Y. Kwok, T. Gietzelt, K. Grundke, H.-J. Jacobasch, and A. W. Neumann, "Contact Angle Measurements and Contact Angle Interpretation. 1. Contact Angle Measurements by Axisymmetric Drop Shape Analysis and a Goniometer Sessile Drop Technique," Langmuir, vol. 13, no. 10, pp. 2880-2894, 1997.
[15] A. W. Neumann, Ed., Applied surface thermodynamics. New York, NY: Dekker, 1996.

[16] H. J. Busscher, A. W. J. van Pelt, P. de Boer, H. P. de Jong, and J. Arends, "The effect of surface roughening of polymers on measured contact angles of liquids," Colloids and Surfaces, vol. 9, no. 4, pp. 319-331, 1984.

[17] W. Weibull, "Wide applicability," J. Appl. Mech., no. 103, p. 33, 1951.

[18] Z. Zhai, C. Gröschel, and D. Drummer, "Tensile behavior of quasi-unidirectional glass fiber/polypropylene composites at room and elevated temperatures," Polymer Testing, vol. 54, pp. 126-133, 2016.

[19] T.-T. Yao, G.-P. Wu, and C. Song, "Interfacial adhesion properties of carbon fiber/polycarbonate composites by using a single-filament fragmentation test," Composites Science and Technology, vol. 149, pp. 108-115, 2017.

[20] A. Kelly and W. R. Tyson, "Tensile properties of fibrereinforced metals: Copper/tungsten and copper/molybdenum," Journal of the Mechanics and Physics of Solids, vol. 13, no. 6, pp. 329-350, 1965.

[21] Omid Zabihi, Mojtaba Ahmadi, Quanxiang Li, Sajjad Shafei, and Minoo Naebe, "Carbon fibres surface modifications using functionalized nanoclays," 2017.

[22] K. Tanaka, M. Suzue, S. Isshiki, M. Shinohara, and T. Katayama, "Evaluation of the interfacial and interlaminar shear strength of carbon fiber reinforced polycarbonate made by a unidirectional sheet," in Ostend, Belgium, 2014, pp. 291299.

[23] J. Li, "Interfacial features of polyamide 6 composites filled with oxidation modified carbon fibres," Proceedings of the Institution of Mechanical Engineers, Part C: Journal of Mechanical Engineering Science, vol. 223, no. 9, pp. 21352141,2009 